\title{
Comparison of the Effect of Passive and Active Recovery, and Self-Myofascial Release Exercises on Lactate Removal and Total Quality of Recovery
}

\author{
İlbilge Özsu ${ }^{1}$, Baris Gurol ${ }^{2}$, Cem Kurt ${ }^{3}$ \\ ${ }^{1}$ Faculty of Sports Sciences, Uşak University, Uşak, Turkey \\ ${ }^{2}$ Faculty of Sports Sciences, Anadolu University, Eskisehir, Turkey \\ ${ }^{3}$ Kırkpınar School of Physical Education and Sports, Trakya University, Edirne, Turkey \\ Correspondence: İlbilge Özsu, Faculty of Sports Sciences, Uşak University, Uşak, TR 64000, Turkey.
}

Received: July 10, $2018 \quad$ Accepted: July 30, $2018 \quad$ Online Published: August 3, 2018

doi:10.11114/jets.v6i9a.3511

URL: https://doi.org/10.11114/jets.v6i9a.3511

\begin{abstract}
Recovery from exercise-induced fatigue is crucial for subsequent performance. Self-myofascial release (SMR) using a foam roller is an alternative to active recovery (AR). This study aims to compare the effects of passive recovery (PR), $\mathrm{AR}$, and SMR on blood lactate [ $\left.\mathrm{La}^{-}\right]$removal and total quality of recovery (TQR). Twenty-two well trained male athletes (age: 22.6 \pm 2.9 years) underwent three testing sessions conducted 72 hours apart but at the same time of each day in a randomized order. After determining resting [ $\left.\mathrm{La}^{-}\right]$and heart rate (HR), the subjects completed a Wingate anaerobic test (WAnT), triggering muscular fatigue. HR and $\left[\mathrm{La}^{-}\right]$were measured three minutes after the WAnT, following which the subjects underwent one of the three different recovery interventions over 15 minutes: PR (lying supine), AR (cycling at $40 \%$ of the estimated maximum HR of the respective subject), and SMR (using foam roller on lower extremity muscles). After each recovery intervention, [ $\left.\mathrm{La}^{-}\right], \mathrm{HR}$, and TQR were measured. There was no statistically significant difference in $\left[\mathrm{La}^{-}\right]$and $\mathrm{HR}$ values obtained before the WAnT test $(\mathrm{p}=0.368, \mathrm{p}=0.691$, respectively) and right after the WAnT test $(0.264, \mathrm{p}=0.629)$ Both AR and SMR were more effective than PR for [La] removal and obtaining a higher TQR $(\mathrm{p}<0.001)$. However, SMR and AR were not superior to one another for blood [ $\left.\mathrm{La}^{-}\right]$removal ( $>>0.05$ ). In contrast, a significantly higher TQR was observed with SMR than AR and $P R(p<0.001)$. Athletes can apply AR or SMR to recover from strenuous exercise. SMR can be an alternative to PR and AR as a recovery tool.
\end{abstract}

Keywords: active recovery, passive recovery, self-myofascial release, blood lactate, total quality of recovery

\section{Introduction}

Exercise-induced muscle fatigue is defined as the decreased ability to generate appropriate amounts of muscle force or power during on-going contractile activity (Finsterer, 2012). However, the basic mechanism underlying muscle fatigue has not been firmly established (Potvin and Fuglevand, 2017). Muscle fatigue is generally attributable to peripheral and central factors (Wan et al., 2017; Allen et al., 2008). Peripheral fatigue is produced by changes at or distal to the neuromuscular junction (depletion of creatine phosphate or accumulation of inorganic phosphate) (Allen et al., 2008). Central fatigue originates at the central nervous system, which decreases the neural drive to the muscle (Wan et al., 2017). Exercise-induced alterations in muscle homeostasis, including hydrogen ion $\left(\mathrm{H}^{+}\right)$accumulation, potassium loss, depletion of high-energy phosphates (ATP and creatine phosphate) and glycogen, loss of calcium homeostasis, or local ischemia, may be some of the causative factors associated with disruption of the muscle excitation-contraction cycle during intense exercise and in post-exercise muscle fatigue (Mika et al, 2007; Steele et al., 2003). It has been known that high-intensity exercise results in increased levels of both intramuscular and circulating levels of lactate [La] (Connolly et al., 2003). This increase in [La], reflecting $\mathrm{H}^{+}$concentration, has been shown to inhibit contractile performance and cause premature fatigue (Connolly et al., 2003; Corder et al., 2000).

Blood [ $\left.\mathrm{La}^{-}\right]$concentration is the most widely used marker of muscular fatigue (Barnett, 2006) occurring during exercise and sports. Fast muscle recovery is necessary for better muscle performance in sports with short inter-bout rest periods (Mika et al., 2007; Hinzpeter et al., 2010). Recovery is defined as the normalization of the $\mathrm{pH}$ within muscle (Lattier et al., 2004). Researchers reported that examples of active and passive recovery (PR) methods used for recovery are 
massage, active recovery (AR), cryotherapy, contrast temperature water immersion therapy, hyperbaric oxygen therapy, nonsteroidal anti-inflammatory drugs, compression garments, stretching, electromyostimulation, and combination modalities (Barnett, 2006). Numerous studies have reported that AR is more effective than PR in removal of [La'] (Connolly et al., 2003; Corder et al., 2000; White and Wells 2015; Menzies et al., 2010; Heyman et al., 2009; Baldari et al., 2005; Spierer et al., 2004).

Typically, 15-25 minutes of resting is thought to be the optimal time for returning pH levels to normal after performing moderate intensity exercise (Bond et al., 1991). PR is simple resting, often in the form of sitting, lying down, or stretching (Warren et al., 2015). AR, wherein athletes participate in low to moderate intensity active movement (exercise intensity of $30-60 \%$ of the estimated maximum $\mathrm{HR}$ [HR $\mathrm{Hax}_{\max }$ of the person who is exercising), is often cardiovascular in nature in an effort to increase vasodilatation, increase oxygen-rich blood flow to the muscle, and remove blood [La-] (Corder et al., 2000; Monedero and Donne 2000). AR has been shown to enhance [La'] clearance from type II skeletal muscle fibers through facilitating its oxidation by adjacent type I fibers (Baldari et al., 2005).

The aim of this study was to compare AR, PR, and SMR with a foam roller on [La'] removal and total quality of recovery (TQR). We hypothesized that 1) AR and SMR are more effective than PR in removal of [La']; 2) SMR is superior to AR in removal of [ $\left.\mathrm{La}^{-}\right]$and obtaining a higher TQR score.

\section{Method}

Twenty-two well trained male athletes from team sports (basketball, soccer, etc.) volunteered to participate in this study. Descriptive data of the subjects are presented in Table 1 . The inclusion criteria were: a) aged $\geq 18$ years, b) having an active team sports license c) had no pre-existing injury or muscular soreness. Subjects who were using an ergogenic aid and had an active lower extremity injury or muscle soreness were excluded from the study. Each subject was instructed to refrain from strenuous physical activity for 24 hours prior to testing. They were also informed to abstain from caffeine or alcohol consumption for 12 hours and otherwise continue their regular dietary habits. All subjects were verbally informed of the procedures, the potential risk and benefits of the study, and if willing to participate, were required to provide their written informed consent prior to their enrollment in the study. This study was approved by the ethics committee of the Eskisehir Osmangazi University (protocol number: 80558721/53) in accordance with the Declaration of Helsinki.

Table 1. Descriptive statistics of participants

\begin{tabular}{lc}
\hline & Participants (n=22) \\
& Mean \pm SD \\
\hline Age (y) & $22.6 \pm 2.9$ \\
Height (cm) & $182.0 \pm 9.5$ \\
Mass (kg) & $78.9 \pm 12.4$ \\
General training age (m) & $139.6 \pm 20.1$ \\
Training frequency (h/w) & $9.6 \pm 0.6$ \\
\hline SD: standard deviation; w: week; m: month; y: year. &
\end{tabular}

\subsection{Data Collection Procedure}

The detailed experimental design flowchart is shown in Figure 1. Each recovery session started with the subject lying in the supine position for 15 minutes. During this period, resting heart rate (HR) was followed and at the end of this period, resting blood $\left[\mathrm{La}^{-}\right]$was measured and right after this, the subject warmed up (5 minute warming up with light cycling resistance and 5 second of sprint cycling at the end of every consecutive minute). After two minutes resting, subjects completed a standardized WAnT and average mean power (R-AP). Right after the WAnT, the rating of perceived exertion (RPE) score was recorded and after 3 minutes of the WAnT, HR, and [La-] were recorded. After this, the subject began one of the recovery interventions (passive, active, or SMR). One minute after the recovery, HR, [La-] and TQR points (TQR) were recorded. In this study, there were three testing sessions, with each session performed at the same time of the day with a 72-hour interval. 


\begin{tabular}{|c|c|c|c|c|}
\hline DAY 1 & \multirow{8}{*}{$\frac{\mathfrak{n}}{\mathfrak{n}}$} & DAY 2 & \multirow{8}{*}{$\frac{\mathfrak{n}}{\mathfrak{n}}$} & DAY 3 \\
\hline $\begin{array}{l}\text { Lying in a supine position } \\
\text { during } 15 \text { minute. } \\
\text { Recording resting HR and } \\
\text { resting [La] }\end{array}$ & & $\begin{array}{l}\text { Lying in a supine position } \\
\text { during } 15 \text { minute. } \\
\text { Recording resting } \mathrm{HR} \text { and } \\
\text { resting [La] }\end{array}$ & & $\begin{array}{l}\text { Lying in a supine position } \\
\text { during } 15 \text { minute. } \\
\text { Recording resting } \mathrm{HR} \text { and } \\
\left.\text { resting [ } \mathrm{La}^{-}\right]\end{array}$ \\
\hline $\begin{array}{l}5 \text { minute warming up with } \\
\text { light cycling resistance and } \\
5 \text { second of sprint cycling } \\
\text { at the end of every } \\
\text { consecutive minute }\end{array}$ & & $\begin{array}{l}5 \text { minute warming up with } \\
\text { light cycling resistance and } \\
5 \text { second of sprint cycling } \\
\text { at the end of every } \\
\text { consecutive minute }\end{array}$ & & $\begin{array}{l}5 \text { minute warming up with } \\
\text { light cycling resistance and } \\
5 \text { second of sprint cycling } \\
\text { at the end of every } \\
\text { consecutive minute } \\
\end{array}$ \\
\hline $\begin{array}{l}\text { WAnT, } \\
\text { R-AP (W/kg) }\end{array}$ & & $\begin{array}{l}\text { WAnT, } \\
\text { R-AP }(\mathrm{W} / \mathrm{kg})\end{array}$ & & $\begin{array}{l}\text { WAnT, } \\
\text { R-AP (W/kg) }\end{array}$ \\
\hline $\begin{array}{l}3^{\text {rd }} \text { minute after WAnT, } \\
\text { recording } \mathrm{HR} \text { and }\left[\mathrm{La}^{-}\right]\end{array}$ & & $\begin{array}{l}3^{\text {rd }} \text { minute after WAnT, } \\
\left.\text { recording HR and [ } \mathrm{La}^{-}\right]\end{array}$ & & $\begin{array}{l}3^{\text {rd }} \text { minute after WAnT, } \\
\left.\text { recording HR and [ } \mathrm{La}^{-}\right]\end{array}$ \\
\hline $\begin{array}{l}\text { RANDOMIZED } \\
\text { INTERVENTION }\end{array}$ & & $\begin{array}{l}\text { RANDOMIZED } \\
\text { INTERVENTION }\end{array}$ & & $\begin{array}{l}\text { RANDOMIZED } \\
\text { INTERVENTION }\end{array}$ \\
\hline $\begin{array}{l}\text { Lying in a supine position } \\
\text { for } 15 \text { minute }\end{array}$ & & $\begin{array}{l}\text { Cycling in intensity of } 40 \\
\% \text { of estimated } \mathrm{HR}_{\max } \text { of } \\
\text { the subject for } 15 \text { minutes }\end{array}$ & & $\begin{array}{l}\text { Foam rolling to each side of } \\
\text { the hip, iliotibial band, } \\
\text { quadriceps, hamstring, } \\
\text { gastrocnemius ,tibialis } \\
\text { anterior for } 15 \text { minutes } \\
(3 \times 30 \mathrm{sec} \text { with } 10 \mathrm{sec} \text { rest }) \text {. }\end{array}$ \\
\hline $\begin{array}{l}\text { Recording HR, [La'] } \\
\text { and TQR }\end{array}$ & & $\begin{array}{l}\text { Recording HR, [La'] } \\
\text { and TQR }\end{array}$ & & $\begin{array}{l}\text { Recording HR, [La'] } \\
\text { and TQR }\end{array}$ \\
\hline
\end{tabular}

Figure 1. Flowchart of experimental design

PR: passive recovery; AR: active recovery; SMR: self-myofascial release; R-AP: relative average power; W: watt; [La']: blood lactate; HR: heart rate; TQR: total quality recovery; RPE: rating of perceived exertion.

\subsection{Body Mass and Height}

Body mass and height of the subjects were measured with a digital device (SECA,769-Turkey).

Heart rate and blood lactate. HR and blood [ $\left.\mathrm{La}^{-}\right]$were measured three times in the study, prior to the WAnT, at the $3^{\text {rd }}$ minute after the WAnT, and the $1^{\text {st }}$ minute after the recovery protocol. During the study, the HR of the subject was followed with a telemetric HR monitor (Polar S810i-Finland). [La'] was determined from fingerstick blood samples (EKF Lactate Scout Analyzer-USA). Blood samples were taken from the ring finger of the subject.

\subsection{The Wingate Anaerobic Test}

The WAnT test was used to trigger muscular fatigue and stimulate [La] production. None of our subjects were accustomed to competing in high-intensity activities which continued for 30 seconds (non-intermittent). Therefore, we hypothesized that the WAnT might trigger muscular fatigue. The WAnT began with a 5-minute warm-up period with light cycling resistance and 5 seconds of sprint cycling at the end of every consecutive minute (Atanasov et al., 2015). After a 2-minute rest period, the subject pedaled as fast as possible on a cycle ergometer (Monark Ergometer, 874 E-Sweden) set at a resistance of $0.075 \mathrm{kp} . \mathrm{kg}^{-1}$ body mass (BM) (Finsterer, 2012; Ramírez et al., 2016). Strong verbal encouragements were provided equally to all subjects during each WAnT. At the end of the WAnT, MP and R-AP were recorded by the computer software of the Monark Ergometer.

\subsection{Rating of Perceived Exertion (RPE)}

The RPE from the WAnT was assessed by the Borg scale (scale ranging from "no exertion at all" (6 points) to "maximal effort" (20 points) (Borg et al., 1985).

\subsection{Passive Recovery (PR)}

Subjects quietly laid in a supine position for 15 minutes for the PR (Pinar et al., 2012).

\subsection{Active Recovery (AR)}

Subjects cycled for 15 minutes at an intensity of $40 \%$ of their own estimated $\mathrm{HR}_{\max }$ (Warren et al., 2015). The target HR for AR was determined by the Karvonen formula (Hansen et al., 2012). During cycling, the subject was verbally encouraged to keep his/her own target HR and HR was followed on a telemetric HR monitor.

\subsection{Self-Myofascial Release Exercise With Foam Roller (SMR)}

The subject rolled a grid foam roller cylinder (height: 13 inches, diameter: 5.5 inches; Trigger Point-USA) from the top of the selected muscle to the bottom and then returned to the starting position (Healey et al., 204). Rolling cadence was 
set as 50 beats per minute (bpm) with an online metronome (Pearcey et al., 2015). SMR exercises were applied to each side of the hamstrings, quadriceps, hip, iliotibial band, gastrocnemius, and tibialis anterior as $3 \times 30$ seconds with a 10 -second inter-set passive rest. The subject was allowed a 30 -second rest between exercises. Because there is no consensus on how much pressure is needed during SMR, we encouraged our subjects to apply as much pressure as they could during SMR.

\subsection{Total Quality of Recovery}

After each recovery intervention, the subject evaluated the recovery quality of their own recovery by the TQR scale (scale ranging from "very poor recovery" (6 points) to "very good recovery" (20 points) (Pinar et al., 2012).

\section{Results}

\subsection{Statistics and Data Analysis}

IBM $^{\circledR}$ SPSS $^{\circledR}$ Statistics for Windows version 23 software (IBM® Corp., 2016, Armonk, NY) was used for the data analysis. Normal distribution of residuals of related data was tested using the Shapiro-Wilk test. The effectiveness of each recovery intervention for 15 minutes was assessed using one-factor repeated measures analysis of variance with the post hoc Bonferroni method for pairwise comparisons for significant results. Mauchly's Sphericity test was used to check for sphericity assumption. When the normality condition was not provided, the Friedman Test was used for variance analysis and the Wilcoxon signed-rank test was performed for paired comparisons. Since factorial ANOVA assumptions were met only for [ $\left.\mathrm{La}^{-}\right]$variable, $3 \times 2$ two way repeated measures ANOVA test was performed just on the $\left[\mathrm{La}^{-}\right]$variable to reveal possible interaction effect between factors (Intervention $\times$Time). Therefore, differences in other variables between interventions were examined using Wilcoxon signed rank test after a significant Friedman test result. The statistical significance level was set at $\mathrm{p}<0.05$ for all analyses.

The results of the Friedman test showed that there was no statistically significant difference in [La'] and HR values obtained before the WAnT test $(\mathrm{p}=0.368, \mathrm{p}=0.691$, respectively) and rigth after the WAnT test $(0.264, \mathrm{p}=0.629)$ According to this result, it can be said that evaluated fatigue levels of participants were similar when they came to the laboratory and they were affected similarly by exhaustive effect generated up by WAnT test before the recovery intervention (see Table 2). R-AP values obtained from the WAnT tests performed in order to create muscular fatigue were not found to be statistically different from each other (see Table 2). In this case, it was concluded that the training loads made up of the WAnT tests were at similar levels.

However, the RPE values obtained right after the WAnT tests were statistically significantly different between SMR and other recovery interventions and the maximum statistical difference was observed in between the RPE values after the WAnT test which was performed before the SMR and PR interventions $(\mathrm{p}<0.001)$. Therefore, it was determined that the WAnT tests performed in this study were perceived at different exertional levels by the participants. Mean percentage change and pairwise comparison values related to the test are shown in Table 3. It was determined that the three different 15 -minute recovery methods have a statistically significant effect on perceived recovery related to the TQR score; the biggest statistically significant effect in pairwise comparison was found between the SMR and PR methods $(\mathrm{p}<0.01)$ (Table 3).

Table 2. Statistical values of R-AP, baseline of La and HR, TQR and RPE related to different intervention days

\begin{tabular}{lllllll}
\hline \multicolumn{7}{c}{ Recovery Intervention Day } \\
\hline & PR & AR & SMR & F or $\chi^{2}$ & $\mathrm{p}$ & $\eta_{\mathrm{p}}{ }^{2}$ \\
\hline R-AP $\left(\mathrm{W} \cdot \mathrm{kg}^{-1}\right)$ & $7.06 \pm 0.69$ & $7.14 \pm 0.73$ & $6.96 \pm 0.48$ & $1.59(\mathrm{~F})$ & 0.215 & 0.071 \\
Baseline $\left[\mathrm{La}^{-}\right](\mathrm{mM} / \mathrm{L})$ & $1.45[0.98-1.70]$ & $1.40[1.20-1.85]$ & $1.50[1.40-1.85]$ & $2.00\left(\chi^{2}\right)$ & 0.368 & - \\
Baseline HR $(\mathrm{bpm})$ & $68.5[59.5-82.5]$ & $73.0[67.3-80.3]$ & $69.0[62.8-76.5]$ & $0.74\left(\chi^{2}\right)$ & 0.691 & - \\
{$[\mathrm{La}]$ right after WAnT $(\mathrm{mM} / \mathrm{L})$} & $10.5 \pm 2.3$ & $11.3 \pm 2.5$ & $10.5 \pm 2.5$ & $1.37(\mathrm{~F})$ & 0.264 & 0.061 \\
HR right after WAnT (bpm) & $109[80-128]$ & $110[77-136]$ & $110[73-124]$ & $0.93\left(\chi^{2}\right)$ & 0.629 & - \\
TQR & $10.0[9.0-12.0]$ & $13.0[13.0-14.0]$ & $15.0[15.0-17.0]$ & $21.2\left(\chi^{2}\right)$ & $<0.001^{*}$ & - \\
RPE & $13.0[14.0-15.0]$ & $13.8[15.0-15.5]$ & $15.0[17.0-18.0]$ & $32.0\left(\chi^{2}\right)$ & $<0.001^{*}$ & - \\
\hline
\end{tabular}

Descriptive statistics are reported as either mean \pm standard deviation or median [25 percentile -75 percentile]; PR: passive recovery; AR: active recovery; SMR: self-myofascial release; F: F value in ANOVA; $\chi^{2}$ : chi-square, $\eta_{\mathrm{p}}{ }^{2}$ : partial eta square, R-AP: relative average power; W: watt; [La']: blood lactate; HR: heart rate; bpm: beat per minute; TQR: total quality recovery; RPE: rating of perceived exertion.

${ }^{*} \mathrm{p}<0.05$ 
Table 3. Comparison of TQR and RPE scores

\begin{tabular}{|c|c|c|c|c|c|}
\hline & $\begin{array}{l}\text { Pairwise } \\
\text { Comparison }\end{array}$ & $\Delta$ & $\mathrm{p}$ & $\mathrm{Z}$ & ES \\
\hline \multirow{4}{*}{ RPE } & $\mathrm{PR}-\mathrm{AR}$ & $-1.00[-2.00--0.25]$ & $0.033 *$ & -2.13 & 0.32 \\
\hline & $\mathrm{PR}-\mathrm{SMR}$ & $-3.00[-4.00--1.75]$ & $<0.001 *$ & -3.94 & 0.59 \\
\hline & AR-SMR & $-2.00[-3.00--1.75]$ & $<0.001 *$ & -3.96 & 0.60 \\
\hline & $\mathrm{PR}-\mathrm{AR}$ & $-3.00[-4.00--1.00]$ & $<0.001 *$ & -3.77 & 0.57 \\
\hline \multirow[t]{2}{*}{ TQR } & PR-SMR & $-6.00[-7.00--3.00]$ & $<0.001 *$ & -3.83 & 0.58 \\
\hline & AR-SMR & $-3.00[-4.00--1.75]$ & $<0.001 *$ & -3.74 & 0.56 \\
\hline
\end{tabular}

Descriptive statistics are reported as median [25 percentile - 75 percentile]; PR: passive recovery; AR: active recovery; SMR: self-myofascial release; RPE: rating of perceived exertion; TQR: total quality of recovery; $\Delta$ : difference; ES: effect size for Wilcoxon signed rank test $(r ; 0.1=$ small, $0.3=$ medium, $0.5=$ large effect size $)$; $Z$ : $Z$ value in Wilcoxon signed rank test

$* \mathrm{p}<0.05$

Two way repeated measures ANOVA results revealed that there was a significant interaction $(\mathrm{F}[2,42]=13.3, \mathrm{p}<0.001$, $\eta_{\mathrm{p}}{ }^{2}=0.387$ ) between RI and Time indicating that change patterns in [La'] over 15 minutes were different between RIs. Also significant main effects were found for both RI $\left(F[2,42]=6.43, p=0.004, \eta_{p}^{2}=0.234\right)$ and Time $(F[1,21]=$ 263.2, $\left.\mathrm{p}<0.001, \eta_{\mathrm{p}}^{2}=0.926\right)$. Lactate reductions $(\Delta)$ were significantly greater after $\mathrm{AR}(\mathrm{p}<0.001)$ and $\mathrm{SMR}(\mathrm{p}<$ 0.001) interventions when compared to PR (Table 4). However, no significant difference were found in lactate reductions between AR and SMR $(\mathrm{p}=1.00)$. According to this result, it was found that SMR and AR are more effective than PR to cope with fatigue related to [ $\left.\mathrm{La}^{-}\right]$caused by the WAnT but SMR and AR were not superior to one another.

Friedman test results showed that there was no significant difference in HR changes between recovery interventions $(\mathrm{p}=0.185)$. But it can be said that the biggest value obtained from SMR intervention (see) Table 5).

Table 4. Pairwise comparison of [la $\left.{ }^{-}\right]$values between different recovery interventions

\begin{tabular}{|c|c|c|c|c|c|c|c|c|c|}
\hline \multirow[b]{2}{*}{ RI } & \multirow[b]{2}{*}{ Time } & \multirow[b]{2}{*}{$\begin{array}{l}{\left[\mathrm{La}^{-}\right](\mathrm{mM} / \mathrm{L})} \\
\text { Mean } \pm \mathrm{SD}\end{array}$} & \multirow[b]{2}{*}{$\begin{array}{l}\% \Delta \\
\text { Mean } \pm \text { SD }\end{array}$} & \multicolumn{3}{|c|}{ RM ANOVA for $\% \Delta$} & \multicolumn{3}{|c|}{ Pairwise Comparison } \\
\hline & & & & $\mathrm{F}$ & $\mathrm{p}$ & $\eta_{\mathrm{p}}^{2}$ & & $\mathrm{p}$ & ES \\
\hline PR & $\begin{array}{l}\text { Post-WAnT } \\
\text { Post-RI }\end{array}$ & $\begin{array}{l}11.0 \pm 2.5 \\
7.9 \pm 2.4\end{array}$ & $-27.7 \pm 17.8$ & & & & $\Delta \mathrm{PR}-\Delta \mathrm{AR}:$ & $<0.001$ & 3.60 \\
\hline $\mathrm{AR}$ & $\begin{array}{l}\text { Post-WAnT } \\
\text { Post-RI }\end{array}$ & $\begin{array}{l}11.3 \pm 2.5 \\
5.3 \pm 1.8\end{array}$ & $-52.5 \pm 14.9$ & 28.3 & $<0.001$ & 0.574 & $\Delta \mathrm{PR}-\Delta \mathrm{SMR}:$ & $<0.001$ & 2.41 \\
\hline SMR & $\begin{array}{l}\text { Post-WAnT } \\
\text { Post-RI }\end{array}$ & $\begin{array}{l}10.5 \pm 2.0 \\
5.1 \pm 1.6\end{array}$ & $-51.1 \pm 11.3$ & & & & $\Delta \mathrm{AR}-\Delta \mathrm{SMR}:$ & 1.00 & 0.20 \\
\hline
\end{tabular}

PR: passive recovery; AR: active recovery; SMR: self-myofascial release; RI: recovery intervention; WAnT: Wingate anaerobic test; [La] : blood lactate; $\% \Delta$ : percentage change; RM: Repeated Measures; F: F value in ANOVA; $\eta_{\mathrm{p}}{ }^{2}$ : partial eta square; ES: effect size (Cohen $d ; 0.2=$ small, $0.5=$ medium, $0.8=$ large effect size)

$* \mathrm{p}<0.05$ 
Table 5. HR changes between different recovery interventions

\begin{tabular}{lllll}
\hline & & & \multicolumn{2}{c}{ Friedman Test for $\% \Delta$} \\
\hline RI & Time & HR $(\mathrm{bpm})$ & $\% \Delta$ & $\chi^{2}$ \\
\hline \multirow{2}{*}{ PR } & Post-WAnT & $108.5[98.0-119.3]$ & $-9.0[-14.9--3.9]$ & \\
& Post-RI & $97.5[84.0-105.3]$ & & \\
\multirow{2}{*}{ AR } & Post-WAnT & $109.5[100.8-125.3]$ & $-12.5[-17.0--4.3]$ & 3.38 \\
\multirow{2}{*}{ SMR } & Post-RI & $99.0[84.0-110.0]$ & & 0.185 \\
& Post-WAnT & $110.0[99.3-115.0]$ & $-17.8[-20.6--10.8]$ & \\
& Post-RI & $90.5[86.3-96.0]$ & & \\
\hline
\end{tabular}

Descriptive statistics are reported as median [25 percentile - 75 percentile]; RI: recovery intervention; PR: passive recovery; AR: active recovery; SMR: self-myofascial release; HR: heart rate; bpm: beat per minute; \% $\Delta$ : percentage change; $\chi^{2}$ : chi-squared test

$* \mathrm{p}<0.05$

\section{Discussion}

This study primarily aimed to investigate if SMR might be an alternative to AR for removal of blood [La'], which is an accepted physiological indicator for recovery, and getting a higher TQR score, which is an accepted psychological indicator of recovery. The results from the present study indicated that: a) both AR and SMR were more effective than PR in terms of removal of [ $\left.\mathrm{La}^{-}\right]$and obtaining a higher TQR score; b) however, SMR and AR were not superior to one another in terms of removal of [La']; c) moreover, a higher TQR score was observed with SMR when compared to AR and PR. In view of these results, our first hypothesis was verified; however, the second hypothesis was only partially verified, since SMR was not superior to AR in removal of [ $\left.\mathrm{La}^{-}\right]$.

Nédélec et al. (2013) reported that $81 \%$ of the French Professional soccer team performed AR immediately after the match and/or on the following days. Numerous researchers argued that AR is more effective than PR in removal of [La'] and decreased muscle soreness (Corder et al., 2000; Hinzpeter et al., 2014; Menzies et al., 2010; Mika et al., 2016; Ali et al., 2012; Dorado et al., 2004; Sairyo et al., 2003; Bogdanis et al., 1996;). The positive effects of AR associated with blood flow to recovering muscle are from phosphocreatine (PCr) resynthesis and pH recovery (Quistorff et al., 1993). It has been well known that adequate blood flow to the recovering muscle will increase oxygen delivery and, therefore, enhance PCr resynthesis (Sahlin et al., 1979), while at the same time [ $\left.\mathrm{La}^{-}\right]$and $\mathrm{H}^{+}$will be removed faster due to the greater $\left[\mathrm{La}^{-}\right]$and $\mathrm{H}^{+}$gradients between the muscle and blood (Bogdanis et al., 1996). An increased muscle [La $\left.{ }^{-}\right]$and $\mathrm{H}^{+}$ removal has been shown to result in a faster recovery of muscle performance (Renaud, 1989).

On the other hand, a considerable number of researchers proposed that AR was not superior to PR for recovery or that PR is more effective than AR in recovery, depending on [ $\left.\mathrm{La}^{-}\right]$removal (Andersson et al., 2010; Dupont et al., 2007; Toubekis et al., 2006; Dupont et al., 2004; Fairchild et al., 2003). Choui et al. (1994) suggested that PR following intense exercise results in a greater amount of muscle glycogen resynthesis than AR over the same duration. Interestingly, Fairchild et al. (2003) reported that AR impairs glycogen repletion in skeletal muscle due to an unfavorable hormonal environment, such as higher plasma catecholamines and lower insulin levels. The positive effects of PR on performance were attributed to a slower decline in the oxyhemoglobin, suggesting that PR allows higher muscular reoxygenation than AR and, therefore a higher PCr resynthesis (Dupont et al., 2004). In the presence of equivocal results, the question arises as to which recovery is more effective in removal of [ $\left.\mathrm{La}^{-}\right]$. The study by Dupont et al. (2007) revealed that the effect of the recovery type on performance might be linked to the exercise intensity performance criteria, recovery duration, and intensity of the recovery.

Regarding the effectiveness of SMR on recovery, several studies reported that SMR has an effect on recovery depending on decreased muscle soreness and increased pressure-pain threshold score following delayed-onset muscle soreness (Pearcey et al., 2015; Casanova et al., 2018). However, D’Amico and Gillis (2017) reported that SMR has no effect on the perception of muscle soreness score (by a Pain Test FPN 100 Algometer), but affects recovery of agility performance following exercise-induced muscle damage.

SMR is believed to have effects similar to massage according to the American Massage Therapy Association. Although the main mechanism is not known for recovery from muscular fatigue after SMR, it is generally attributed to decreased edema, enhanced blood [ $\left.\mathrm{La}^{-}\right]$removal, and enhanced tissue healing, which are mainly due to the increase in muscular blood flow (Paolini, 2009). According to Pearcey et al. (2015) increased blood flow hinders the margination of neutrophils and reduces prostaglandin production, subsequently decreasing inflammation.

We could not find any studies other than the studies by D'amico and Paolone (2017) and Cè et al. (2013) which compared the effects of SMR and other recovery methods on recovery via [ $\left.\mathrm{La}^{-}\right]$removal. In contrast to our study, D'amico and Paolone (2017) reported that SMR had no effect on the removal of [La']; this study also argued that light 
exercise was a means of AR for minimizing fatigue-induced decrements in performance during successive exercise bouts. Cè et al. (2013) also reported that neither massage (deep and superficial massage) nor passive stretching were effective alternatives to AR in accelerating [ $\left.\mathrm{La}^{-}\right]$kinetics after a fatiguing exercise.

Okamoto et al. (2014) reported that SMR using a foam roller increases plasma nitric oxide concentration (NOC) and decreases arterial stiffness in healthy subjects aged $19.9 \pm 0.3$ years. We concluded that recovery from muscle fatigue may be attributed to increasing NOC, which is a known vasoactive substance. However, Casanova et al. (2018) argued that foam roller massage (target muscle gastrocnemius; $6 \times 45$ seconds with a 20 -second rest) did not change the muscular oxygenation in young subjects' responses 48 hours after exercise-induced muscle damage.

Regarding TQR, previous studies have demonstrated strong inverse associations between TQR and biomarkers of muscle damage, such as creatine kinase (Osiecki et al., 2015). According to Osiecki et al. (2015) TQR may be a good predictor of the recovery state in team sports athletes. A study published by Rey et al. (2017) reported that post-training foam rolling exercises may help in restoring muscle soreness, players' perception of TQR, and agility on the following day in professional soccer players.

There were two main limitations in this study. First, the results of the study were limited to recovery from [ $\left.\mathrm{La}^{-}\right]$ following a WAnT. We could not apply several consecutive WAnT with the worry of medical problem which to be occurred after high-intensity exercise. Second, our subjects had no experience with using a foam roller. For experienced players using a foam roller for recovery, results may differ.

In conclusion, our study results show that using a foam roller for SMR seems to be as effective as AR as a recovery tool. Therefore, we suggest that SMR may be an alternative recovery tool after exercise-induced muscular fatigue. Due to contradictory results found in the literature for effects of SMR on recovery, further research is needed to explain this.

\subsection{Acknowledgements}

This study was funded by the Scientific Research Project Unit of the Anadolu University by protocol number of 1705 S552.

4.2 Declaration of conflicting interests

The authors declared no conflicts of interest with respect to the authorship and/or publication of this article.

\section{References}

Ali, S. R., Koushkie, M. J., Asadmanesh, A., \& Salesi, M. (2012). Influence of massage, active and passive recovery on swimming performance and blood lactate. The Journal of sports medicine and physical fitness, 52(2), 122-127.

Allen, D. G., Lamb, G. D., \& Westerblad, H. (2008). Skeletal muscle fatigue: cellular mechanisms. Physiological reviews, 88(1), 287-332. https://doi.org/10.1152/physrev.00015.2007

Andersson, H., Karlsen, A., Blomhoff, R., Raastad, T., \& Kadi, F. (2010). Active recovery training does not affect the antioxidant response to soccer games in elite female players. British journal of nutrition, 104(10), 1492-1499. https://doi.org/10.1017/S0007114510002394

Atanasov, P., Djarova, T., Kalinski, M., Petrov, L., Kaneva, R., Mugandani, S., ... \& Jemni, M. (2015). ACTN3 and AMPD1 Polymorphism and Genotype Combinations in Bulgarian Athletes Performing Wingate Test. Journal of Sports Science, 3(3), 1-10.

Baldari, C., Videira, M., Madeira, F., Sergio, J., \& Guidetti, L. (2005). Blood lactate removal during recovery at various intensities below the individual anaerobic threshold in triathletes. Journal of Sports Medicine and Physical Fitness, 45(4), 460 .

Barnett, A. (2006). Using recovery modalities between training sessions in elite athletes. Sports medicine, 36(9), 781-796. https://doi.org/10.2165/00007256-200636090-00005

Bogdanis, G. C., Nevill, M. E., Lakomy, H. K., Graham, C. M., \& Louis, G. (1996). Effects of active recovery on power output during repeated maximal sprint cycling. European journal of applied physiology and occupational physiology, 74(5), 461-469. https://doi.org/10.1007/BF02337727

Bond, V., Adams, R. G., Tearney, R. J., Gresham, K., \& Ruff, W. (1991). Effects of active and passive recovery on lactate removal and subsequent isokinetic muscle function. The Journal of sports medicine and physical fitness, 31(3), 357-361.

Borg, G., Ljunggren, G., \& Ceci, R. (1985). The increase of perceived exertion, aches and pain in the legs, heart rate and blood lactate during exercise on a bicycle ergometer. European journal of applied physiology and occupational physiology, 54(4), 343-349. https://doi.org/10.1007/BF02337176 
Casanova, N., Reis, J. F., Vaz, J. R., Machado, R., Mendes, B., Button, D. C., ... \& Freitas, S. R. (2018). Effects of roller massager on muscle recovery after exercise-induced muscle damage. Journal of sports sciences, 36(1), 56-63. https://doi.org/10.1080/02640414.2017.1280609

Cè, E., Limonta, E., Maggioni, M. A., Rampichini, S., Veicsteinas, A., \& Esposito, F. (2013). Stretching and deep and superficial massage do not influence blood lactate levels after heavy-intensity cycle exercise. Journal of sports sciences, 31(8), 856-866. https://doi.org/10.1080/02640414.2012.753158

Choi, D., Cole, K. J., Goodpaster, B. H., Fink, W. J., \& Costill, D. L. (1994). Effect of passive and active recovery on the resynthesis of muscle glycogen. Medicine and science in sports and exercise, 26(8), 992-996. https://doi.org/10.1249/00005768-199408000-00010

Connolly, D. A., Brennan, K. M., \& Lauzon, C. D. (2003). Effects of active versus passive recovery on power output during repeated bouts of short term, high intensity exercise. Journal of sports science \& medicine, 2(2), 47.

Corder, K. P., Potteiger, J. A., Nau, K. L., Figoni, S. E., \& Hershberger, S. L. (2000). Effects of active and passive recovery conditions on blood lactate, rating of perceived exertion, and performance during resistance exercise. The Journal of Strength \& Conditioning Research, 14(2), 151-156.

D’Amico, A., \& Paolone, V. (2017). The Effect of Foam Rolling on Recovery Between Two Eight Hundred Metre Runs. Journal of human kinetics, 57(1), 97-105. https://doi.org/10.1515/hukin-2017-0051

D'Amico, A. P., \& Gillis, J. (2017). The influence of foam rolling on recovery from exercise-induced muscle damage. Journal of strength and conditioning research. https://doi.org/10.1519/JSC.0000000000002240

Dorado, C., Sanchis-Moysi, J., \& Calbet, J. A. (2004). Effects of recovery mode on performance, O2 uptake, and O2 deficit during high-intensity intermittent exercise. Canadian journal of applied physiology, 29(3), 227-244. https://doi.org/10.1139/h04-016

Dupont, G., Moalla, W., Guinhouya, C., Ahmaidi, S., \& Berthoin, S. (2004). Passive versus active recovery during high-intensity intermittent exercises. Medicine \& Science in Sports \& Exercise, 36(2), 302-308. https://doi.org/10.1249/01.MSS.0000113477.11431.59

Dupont, G., Moalla, W., Matran, R., \& Berthoin, S. (2007). Effect of short recovery intensities on the performance during two Wingate tests. Medicine \& Science in Sports \& Exercise, 39(7), 1170-1176. https://doi.org/10.1249/mss.0b013e31804c9976

Fairchild, T. J., Armstrong, A. A., Rao, A., Liu, H., Lawrence, S., \& Fournier, P. A. (2003). Glycogen synthesis in muscle fibers during active recovery from intense exercise. Medicine and Science in Sports and Exercise, 35(4), 595-602. https://doi.org/10.1249/01.MSS.0000058436.46584.8E

Finsterer, J. (2012). Biomarkers of peripheral muscle fatigue during exercise. BMC musculoskeletal disorders, 13(1), 218. https://doi.org/10.1186/1471-2474-13-218

Hansen, D., Stevens, A., Eijnde, B. O., \& Dendale, P. (2012). Endurance exercise intensity determination in the rehabilitation of coronary artery disease patients. Sports Medicine, 42(1), 11-30. https://doi.org/10.2165/11595460-000000000-00000

Healey, K. C., Hatfield, D. L., Blanpied, P., Dorfman, L. R., \& Riebe, D. (2014). The effects of myofascial release with foam rolling on performance. The Journal of Strength \& Conditioning Research, 28(1), 61-68. https://doi.org/10.1519/JSC.0b013e3182956569

Heyman, E., DE, B. G., Mertens, I., \& Meeusen, R. (2009). Effects of four recovery methods on repeated maximal rock climbing performance. Medicine and science in sports and exercise, 41(6), 1303-1310. https://doi.org/10.1249/MSS.0b013e318195107d

Hinzpeter, J., Zamorano, Á., Cuzmar, D., Lopez, M., \& Burboa, J. (2014). Effect of active versus passive recovery on performance during intrameet swimming competition. Sports health, 6(2), 119-121. https://doi.org/10.1177/1941738113500769

Lattier, G., Millet, G. Y., Martin, A., \& Martin, V. (2004). Fatigue and recovery after high-intensity exercise Part II: recovery interventions. International journal of sports medicine, 25(07), 509-515. https://doi.org/10.1055/s-2004-820946

Menzies, P., Menzies, C., McIntyre, L., Paterson, P., Wilson, J., \& Kemi, O. J. (2010). Blood lactate clearance during active recovery after an intense running bout depends on the intensity of the active recovery. Journal of sports sciences, 28(9), 975-982. https://doi.org/10.1080/02640414.2010.481721 
Mika, A., Mika, P., Fernhall, B., \& Unnithan, V. B. (2007). Comparison of recovery strategies on muscle performance after fatiguing exercise. American journal of physical medicine \& rehabilitation, 86(6), 474-481. https://doi.org/10.1097/PHM.0b013e31805b7c79

Mika, A., Oleksy, Ł., Kielnar, R., Wodka-Natkaniec, E., Twardowska, M., Kamiński, K., \& Małek, Z. (2016). Comparison of two different modes of active recovery on muscles performance after fatiguing exercise in mountain canoeist and football players. PloS one, 11(10), e0164216. https://doi.org/10.1371/journal.pone.0164216

Monedero, J., \& Donne, B. (2000). Effect of recovery interventions on lactate removal and subsequent performance. International journal of sports medicine, 21(08), 593-597. https://doi.org/10.1055/s-2000-8488

Nédélec, M., McCall, A., Carling, C., Legall, F., Berthoin, S., \& Dupont, G. (2013). Recovery in soccer. Sports Medicine, 43(1), 9-22. https://doi.org/10.1007/s40279-012-0002-0

Okamoto, T., Masuhara, M., \& Ikuta, K. (2014). Acute effects of self-myofascial release using a foam roller on arterial function. The Journal of Strength \& Conditioning Research, 28(1), 69-73. https://doi.org/10.1519/JSC.0b013e31829480f5

Osiecki, R., Rubio, T. B. G., Coelho, R. L., Novack, L. F., Conde, J. H. S., Alves, C. G., \& Malfatti, C. R. M. (2015). The total quality recovery scale (TQR) as a proxy for determining athletes' recovery state after a professional soccer match. J Exerc Physiol, 18(3), 27-32.

Paolini, J. (2009). Review of myofascial release as an effective massage therapy technique. Athletic Therapy Today, 14(5), 30-34. https://doi.org/10.1123/att.14.5.30

Pearcey, G. E., Bradbury-Squires, D. J., Kawamoto, J. E., Drinkwater, E. J., Behm, D. G., \& Button, D. C. (2015). Foam rolling for delayed-onset muscle soreness and recovery of dynamic performance measures. Journal of athletic training, 50(1), 5-13. https://doi.org/10.4085/1062-6050-50.1.01

Pinar, S., Kaya, F., Bicer, B., Erzeybek, M. S., \& Cotuk, H. B. (2012). Different recovery methods and muscle performance after exhausting exercise: comparison of the effects of electrical muscle stimulation and massage. Biology of sport, 29(4), 269. https://doi.org/10.5604/20831862.1019664

Potvin, J. R., \& Fuglevand, A. J. (2017). A motor unit-based model of muscle fatigue. PLoS computational biology, 13(6), e1005581. https://doi.org/10.1371/journal.pcbi.1005581

Quistorff, B., Johansen, L., \& Sahlin, K. (1993). Absence of phosphocreatine resynthesis in human calf muscle during ischaemic recovery. Biochemical Journal, 291(3), 681-686. https://doi.org/10.1042/bj2910681

Ramírez-Vélez, R., López-Albán, C. A., La Rotta-Villamizar, D. R., Romero-García, J. A., Alonso-Martinez, A. M., \& Izquierdo, M. (2016). Wingate anaerobic test percentile norms in colombian healthy adults. The Journal of Strength \& Conditioning Research, 30(1), 217-225. https://doi.org/10.1519/JSC.0000000000001054

Renaud, J. M. (1989). The effect of lactate on intracellular $\mathrm{pH}$ and force recovery of fatigued sartorius muscles of the frog, Rana pipiens. The Journal of physiology, 416(1), 31-47. https://doi.org/10.1113/jphysiol.1989.sp017747

Rey, E., Padrón-Cabo, A., Costa, P. B., \& Barcala-Furelos, R. (2017). The Effects of Foam Rolling as a Recovery Tool in Professional Soccer Players. Journal of strength and conditioning research. https://doi.org/10.1519/JSC.0000000000002277

Sahlin, K., Harris, R. C., \& Hultman, E. (1979). Resynthesis of creatine phosphate in human muscle after exercise in relation to intramuscular $\mathrm{pH}$ and availability of oxygen. Scandinavian journal of clinical and laboratory investigation, 39(6), 551-557. https://doi.org/10.3109/00365517909108833

Sairyo, K., Iwanaga, K., Yoshida, N., Mishiro, T., Terai, T., Sasa, T., \& Ikata, T. (2003). Effects of active recovery under a decreasing work load following intense muscular exercise on intramuscular energy metabolism. International Journal of Sports Medicine, 24(03), 179-182. https://doi.org/10.1055/s-2003-39091

Spierer, D. K., Goldsmith, R., Baran, D. A., Hryniewicz, K., \& Katz, S. D. (2004). Effects of active vs. passive recovery on work performed during serial supramaximal exercise tests. International journal of sports medicine, 25(02), 109-114. https://doi.org/10.1055/s-2004-819954

Steele, D. S., \& Duke, A. M. (2003). Metabolic factors contributing to altered Ca2+ regulation in skeletal muscle fatigue. Acta physiologica scandinavica, 179(1), 39-48. https://doi.org/10.1046/j.1365-201X.2003.01169.x

Toubekis, A. G., Smilios, I., Bogdanis, G. C., Mavridis, G., \& Tokmakidis, S. P. (2006). Effect of different intensities of active recovery on sprint swimming performance. Applied Physiology, Nutrition, and Metabolism, 31(6), 709-716. https://doi.org/10.1139/h06-075 
Wan, J. J., Qin, Z., Wang, P. Y., Sun, Y., \& Liu, X. (2017). Muscle fatigue: general understanding and treatment. Experimental \& molecular medicine, 49(10), e384. https://doi.org/10.1038/emm.2017.194

Warren, C. D., Szymanski, D. J., \& Landers, M. R. (2015). Effects of three recovery protocols on range of motion, heart rate, rating of perceived exertion, and blood lactate in baseball pitchers during a simulated game. The Journal of Strength \& Conditioning Research, 29(11), 3016-3025. https://doi.org/10.1519/JSC.0000000000000487

White, G. E., \& Wells, G. D. (2015). The effect of on-hill active recovery performed between runs on blood lactate concentration and fatigue in alpine ski racers. The Journal of Strength \& Conditioning Research, 29(3), 800-806. https://doi.org/10.1519/JSC.0000000000000677

\section{Copyrights}

Copyright for this article is retained by the author(s), with first publication rights granted to the journal.

This is an open-access article distributed under the terms and conditions of the Creative Commons Attribution license which permits unrestricted use, distribution, and reproduction in any medium, provided the original work is properly cited. 